\title{
Genetics of Non-Alcoholic Fatty Liver and Cardiovascular Disease: Implications for Therapy?
}

\author{
Karthik Chandrasekharan and William Alazawi * \\ Barts Liver Centre, Blizard Institute, Queen Mary University of London, London, United Kingdom
}

Non-alcoholic fatty liver disease (NAFLD) is the most common cause of chronic liver disease worldwide. The most common cause of mortality in NAFLD is cardiovascular disease (CVD), and a key of focus in drug development is to discover therapies that target both liver injury and CVD risk. NAFLD and CVD are complex disease spectra with complex heritability patterns. Nevertheless, genome wide association studies and metaanalyses of these have identified genetic loci that are associated with increased risk of relevant pathological features of disease or clinical endpoints. This review focuses on the genetic risk loci identified in the NAFLD spectrum and asks whether any of these are also risk factors for CVD. Surprisingly, given the shared co-morbidities and risk factors, little

OPEN ACCESS

Edited by:

You Zhou,

Cardiff University, United Kingdom

Reviewed by:

Volker Martin Lauschke, Karolinska Institutet (KI), Sweden

Soumik BasuRay,

UT Southwestern Medical Center, United States

${ }^{*}$ Correspondence: William Alazawi w.alazawi@qmul.ac.uk

Specialty section: This article was submitted to Pharmacogenetics and

Pharmacogenomics,

a section of the journal

Frontiers in Pharmacology

Received: 03 July 2019 Accepted: 07 November 2019 Published: 08 January 2020

Citation:

Chandrasekharan K and Alazawi W (2020) Genetics of Non-Alcoholic

Fatty Liver and Cardiovascular Disease: Implications for Therapy?

Front. Pharmacol. 10:1413.

doi: 10.3389/fphar.2019.01413 robust evidence exists that NAFLD and CVD share genetic risk. Despite this, therapeutic intervention that targets both liver disease and CVD remains an important clinical need and a major focus for pharmaceutical development.

Keywords: non-alcoholic fatty liver disease, non-alcoholic steatohepatitis, cardiovascular disease, genome wide association studies, therapeutics

\section{BODY}

Non-alcoholic fatty liver disease (NAFLD) affects over $20 \%$ of people in the West, and up to one third of people living in South America or the Middle East (Younossi, 2019). NAFLD is defined by the presence of hepatic steatosis in the absence of a secondary cause (e.g., excessive alcohol consumption or drugs). It is associated with hypertension and a number of metabolic co-morbidities, including obesity, type 2 diabetes mellitus (T2DM), hyperlipidemia, and metabolic syndrome (Younossi et al., 2016). NAFLD is a disease spectrum that comprises simple steatosis, non-alcoholic steatohepatitis (NASH), and fibrosis which can lead to cirrhosis and hepatocellular carcinoma (HCC) (Chalasani et al., 2012; White et al., 2012; Alexander et al., 2019b). The determinants of progression through this spectrum are not completely understood, but increased visceral adiposity, insulin resistance, lipotoxicity, inflammation, environmental factors such as diet as well as genetics are likely to play a role. There are currently no drugs licensed for the treatment of the NAFLD spectrum although many are in development.

A large body of evidence indicates that cardiovascular disease (CVD) is a common cause of death among patients with NAFLD (Rafiq et al., 2009; Söderberg et al., 2010; Stepanova and Younossi, 2012; Angulo et al., 2015; Targher et al., 2016; Mahfood Haddad et al., 2017; Younossi et al., 2017) although this is not a universal finding (Lazo et al., 2011; Wu et al., 2016; Zeb et al., 2016; Alexander et al., 2019a; Morrison et al., 2019). Some of this dissonance may relate to variable adjustment for existing risk factors including diabetes, obesity, smoking, ethnicity, and social deprivation. Therefore, while some evidence suggests increased CVD risk, and the two disease states share common pathological 
mechanisms [e.g., oxidative stress, inflammation, and endothelial dysfunction (Liu and Lu, 2014; Francque et al., 2016)], a causal relationship has yet to be proven.

Nevertheless, there is a drive to discover therapeutic strategies that combine hepatic efficacy with reducing CVD risk in this multi-morbid population who carry many metabolic risk factors. One possible solution may lie in the genetics of these conditions. If NASH and CVD are closely linked, it is plausible to hypothesize that genetic variants that confer adverse risk and that are shared between disease states encode potential therapeutic targets that may meet treatment goals. Over 163 genetic loci are associated with CVD (Erdmann et al., 2018), and a much smaller number of loci with NAFLD spectrum (Eslam et al., 2018) but there is minimal overlap between these groups of genes. Here, we review the genetic associations with disease states in the NAFLD spectrum and the evidence, if any, of their role in CVD.

\section{Genetics of Non-Alcoholic Fatty Liver Disease}

Genome wide association studies (GWAS) have enabled the association of genetic polymorphisms with disease state or treatment response (Eslam et al., 2018). Limitations of GWAS include absence of causality, requirement for very large sample sizes and difficulties in interpreting heritability in complex polygenic conditions such as NAFLD (Tam et al., 2019). Different endpoints have been used in NAFLD GWAS including histology, imaging-based hepatic fat content, serum liver enzymes, and presence of HCC, contributing to heterogeneity. Here we focus primarily on candidate NAFLD risk genes with consistent results in discovery GWAS or meta-analyses of GWAS, and validated using candidate gene studies, a strategy described in a recent study clustering NAFLD associated genes (Brouwers et al., 2019). We also highlight other genes not identified with GWAS, but have significant associations with CVD in retrospective studies or meta-analyses of retrospective studies, and outline their association with NAFLD (Table 1).

\section{Patatin-Like Phospholipase Domain- Containing Protein 3 (Aliases: Adiponutrin, Calcium-Independent Phospholipase A2-Epsilon, or Acylglycerol O-Acyltransferase)}

PNPLA3 hydrolyses triglycerides and retinyl esters (Huang et al., 2011) and is associated with NAFLD in GWAS (Romeo et al., 2008). The I148M variant (isoleucine to methionine substitution at amino acid position 148) of PNPLA3 has reduced hydrolase activity and impairs retinyl ester release, resulting in accumulation of triglycerides and retinyl esters within hepatocytes and stellate cells and increased hepatic fat content (Pingitore et al., 2014; Pirazzi et al., 2014; BasuRay et al., 2017). Upregulation of wildtype PNPLA3 reduces secretion of matrix metalloproteinases and tissue inhibitor of metalloproteinases, protecting against fibrosis (Pingitore et al., 2016).

PNPLA3 I148M (rs738409 C > G) is significantly associated with imaging-assessed hepatic fat content, adjusted for body mass index (BMI), diabetes status, ethanol use, and ethnicity ( $\mathrm{p}=$ $\left.7.0 \times 10^{-14}\right)$ (Romeo et al., 2008). This allele significantly increases the risk of hepatic steatosis and fibrosis independent of age, sex, BMI, and homeostatic model of insulin resistance (HOMA) index, in a "dose-dependent" manner, with intermediate severity of steatosis in heterozygotes and more severe steatosis in homozygotes (G/G) (Sookoian et al., 2009; Valenti et al., 2010). Cross-sectional studies show the $G$ allele is more frequent in histologically confirmed steatosis (frequency: $49.2 \%, \mathrm{p}=2 \times 10^{-3}$ ) and NASH (frequency: $51.8 \%, \mathrm{p}=4 \times 10^{-26}$ ) compared with normal controls (frequency: 22.8\%). Risk of bridging fibrosis increases with each G allele (OR 1.50, 95\% CI 1.19-1.89), independently of steatosis and inflammation (Rotman et al., 2010). The rs738409 $\mathrm{C}>\mathrm{G}$ polymorphism is also associated with increased HCC risk (OR: 2.046, 95\% CI 1.47-2.84, $\chi^{2}=18.50, \mathrm{p}<0.0001$ ), and additive modeling showed that $\mathrm{G} / \mathrm{G}$ homozygosity conferred a fivefold increase in risk compared with $\mathrm{C} / \mathrm{C}$ homozygous NAFLD controls (OR: 5.05, 95\% CI 1.47-17.29, p = 0.01) (Liu et al., 2014a). A meta-analysis of 24 studies with a total of 9,195, mostly Caucasian, patients concluded that PNPLA3 I148M is significantly associated with increased risk of advanced fibrosis in individuals with NAFLD (OR: 1.23, 95\% CI 1.10-1.37) and of HCC (OR: 1.67, 95\% CI 1.27-2.21) in patients with NAFLD (Singal et al., 2014).

In non-Caucasian cohorts, there is also strong evidence for an association of PNPLA3 with NAFLD. In two Japanese cohorts the PNPLA3 rs738409 variant was significantly associated with NAFLD (OR: 1.66, 95\% CI 1.43-1.94, $\mathrm{p}=1.4 \times 10^{-10}$ ), and, in particular, a more severe histological subtype (Kawaguchi et al., 2012; Kitamoto et al., 2013), with similar findings in a large Korean cohort (Chung et al., 2018). PNPLA3 I148M is therefore strongly associated with the NAFLD spectrum in both Caucasian and non-Caucasian cohorts.

\section{Transmembrane 6 Superfamily 2}

TM6SF2 encodes a protein that localizes to the endoplasmic reticulum (ER)-Golgi apparatus of hepatocytes, and increases secretion of triglyceride-rich lipoproteins; reduced TM6SF2 expression increases hepatic triglyceride content (Mahdessian et al., 2014). TM6SF2 E167K variant (rs58542926 C > T) is associated with increased levels of hepatic triglyceride content measured using ${ }^{1} \mathrm{H}-\mathrm{MRS}$ (independently of PNPLA3 I148M), raised serum alanine transaminase (ALT), and reduced serum cholesterol and triglycerides, in a multi-ethnic cohort (Kozlitina et al., 2014). The association with serum ALT was confirmed in two further cohorts, of 8,585 European Americans and 73,532 individuals from two Copenhagen-based studies (Kozlitina et al., 2014). This variant is associated with increased hepatic fibrosis $\left(\beta: 0.549 \pm 0.135,95 \%\right.$ CI $\left.0.285-1.813, \mathrm{p}=5.57 \times 10^{-5}\right)$, again independently of PNPLA3 I148M (Liu et al., 2014b). After adjusting for confounding variables, the co-existence of PNPLA3 rs738409 and TM6SF2 rs58542926 in a Korean cohort increased the risk of NASH (OR per risk allele: $2.03,95 \%$ CI 1.50-2.73 p < 0.001 ) and significant fibrosis (OR for each risk allele: 1.61, 95\% CI 1.19-2.17, p < 0.002) (Koo et al., 2018) with similar findings from a Chinese cohort (OR for each allele 1.52, regression line 
TABLE 1 | Summary of genetic variants and their effects on non-alcoholic fatty liver disease/non-alcoholic steatohepatitis.

\begin{tabular}{|c|c|c|}
\hline Genetic variant & Effect & Reference(s) \\
\hline PNPLA3 I148M & $\begin{array}{l}\text { Increases hepatic fat } \\
\text { content, and risk of } \\
\text { hepatic steatosis, fibrosis, } \\
\text { and HCC }\end{array}$ & $\begin{array}{l}\text { (Romeo et al., 2008; } \\
\text { Sookoian et al., 2009; Liu } \\
\text { et al., 2014a) }\end{array}$ \\
\hline TM6SF2 E167K & $\begin{array}{l}\text { Increases levels of hepatic } \\
\text { triglyceride content, ALT, } \\
\text { and increased risk of } \\
\text { hepatic fibrosis }\end{array}$ & $\begin{array}{l}\text { (Kozlitina et al., 2014; Liu } \\
\text { et al., 2014b) }\end{array}$ \\
\hline MBOAT7 rs614738 & $\begin{array}{l}\text { Increases hepatic } \\
\text { triglyceride content, and } \\
\text { risk of hepatic steatosis, } \\
\text { fibrosis, and HCC }\end{array}$ & $\begin{array}{l}\text { (Buch et al., 2015; } \\
\text { Mancina et al., 2016; } \\
\text { Donati et al., 2017) }\end{array}$ \\
\hline GCKR rs780094 & $\begin{array}{l}\text { Increased hepatic } \\
\text { steatosis and fibrosis }\end{array}$ & $\begin{array}{l}\text { (Speliotes et al., 2011; } \\
\text { Petta et al., 2014) }\end{array}$ \\
\hline NCAN P92S & $\begin{array}{l}\text { Increased risk of hepatic } \\
\text { steatosis, lobular } \\
\text { inflammation, and fibrosis }\end{array}$ & $\begin{array}{l}\text { (Speliotes et al., 2011; } \\
\text { Gorden et al., 2013) }\end{array}$ \\
\hline PPP1R3B rs4240624 & $\begin{array}{l}\text { Increased risk of hepatic } \\
\text { steatosis }\end{array}$ & (Speliotes et al., 2011) \\
\hline PPP1R3B rs6175625 & $\begin{array}{l}\text { Predictor of } \\
\text { ultrasonography } \\
\text { diagnosed NAFLD }\end{array}$ & (Di Costanzo et al., 2018) \\
\hline TRIB1 rs2954021 & $\begin{array}{l}\text { Associated with raised } \\
\text { ALT and increased } \\
\text { risk of histological } \\
\text { or ultrasonography } \\
\text { diagnosed NAFLD }\end{array}$ & $\begin{array}{l}\text { (Chambers et al., 2011; } \\
\text { Kitamoto et al., 2014; Liu } \\
\text { et al., 2019) }\end{array}$ \\
\hline ERLIN1-CHUK-CWF19L1 & $\begin{array}{l}\text { Increased risk of } \\
\text { CT-diagnosed NAFLD and } \\
\text { raised ALT }\end{array}$ & (Feitosa et al., 2013) \\
\hline PEMT V175M & $\begin{array}{l}\text { Increased risk of } \\
\text { histologically diagnosed } \\
\text { NAFLD and NASH, and } \\
\text { ultrasonography/MRS } \\
\text { diagnosed NAFLD }\end{array}$ & (Tan et al., 2016) \\
\hline MTTP 493G > T & $\begin{array}{l}\text { Increased risk of biopsy } \\
\text { proven NAFLD and NASH, } \\
\text { and ultrasonography } \\
\text { diagnosed NAFLD }\end{array}$ & (Zheng et al., 2014) \\
\hline SOD2 rs4880 & $\begin{array}{l}\text { Increased risk of fibrosis } \\
\text { steatohepatitis and fibrosis }\end{array}$ & (Al-Serri et al., 2012) \\
\hline UCP2 866 G > A & $\begin{array}{l}\text { Reduced risk of } \mathrm{NASH} \text {, } \\
\text { more pronounced effect } \\
\text { in those without impaired } \\
\text { fasting glucose or } \\
\text { diabetes mellitus }\end{array}$ & (Fares et al., 2015) \\
\hline
\end{tabular}

$\mathrm{R}^{2}=0.992$ ) (Wang et al., 2016). Thus TM6SF2 E167K is associated with stages of NAFLD independently of PNPLA3 I148M.

\section{Membrane Bound O-Acyltransferase Domain Containing 7}

MBOAT7 is highly expressed in hepatocytes, hepatic stellate cells, and hepatic sinusoidal cells, and the rs641738 T allele increases risk of hepatic triglyceride content and NAFLD spectrum, with each $\mathrm{T}$ allele increasing the risk of steatosis (OR: 1.42, 95\% CI $1.07-1.91, \mathrm{p}=0.015)$, NASH (OR: $1.18,95 \%$ CI 1.00-1.40, $\mathrm{p}=$ 0.05 ), hepatic fibrosis stage F2-4 (OR: $1.30,95 \%$ CI 1.06-1.70, $\mathrm{p}=0.012$ ), and HCC in the absence of advanced fibrosis (OR:
2.10, 95\% CI 1.33-3.31) (Buch et al., 2015; Mancina et al., 2016; Donati et al., 2017). MBOAT7, PNPLA3, and TM6SF2 risk loci confer a stepwise risk of increased hepatic fat content per each additional risk allele (Mancina et al., 2016).

\section{Glucokinase Regulatory Protein}

The GCKR rs780094 polymorphism is significantly associated with CT- and histologically proven hepatic steatosis in GWAS $\left(\mathrm{OR}=1.45, \mathrm{p}=2.59 \times 10^{-8}\right)$ (Speliotes et al., 2011) and in metaanalysis of five studies (2,091 NAFLD cases and 3,003 controls) (OR: 1.25, 95\% CI 1.14-1.36, $\mathrm{p}<0.00001, \mathrm{I}^{2}=0 \%$ ) (Zain et al., 2015). This polymorphism is associated with higher expression of GCKR (Rodríguez et al., 2018), and with reduced risk of T2DM (Sparsø et al., 2008; Onuma et al., 2010). In patients with NAFLD the rs780094 C > T polymorphism is significantly associated with hepatic fibrosis stage $>$ F1 (OR: 2.06, 95\% CI $1.02-1.14, \mathrm{p}=0.0008$ ) (Petta et al., 2014). The rs1260326 P446L variant is not inhibited by fructose-6-phosphate, resulting in increased activity of glucokinase, hepatic uptake of glucose (Beer et al., 2009), and de novo lipogenesis (Anstee and Day, 2013). In individuals who carried GCKR rs1260326, PNPLA3 rs738409, TM6SF2 rs58542926, and MBOAT7 rs641738 variants $(\mathrm{n}=218$ NAFLD/445 total) there was a fivefold increased risk of steatosis (OR: 4.97, 95\% CI 2.51-9.83) (Di Costanzo et al., 2018).

\section{Neurocan Core Protein}

The Speliotes GWAS identified a number of other loci associated with NAFLD. NCAN rs2228603 T variant (P92S) is associated with increased risk of histological steatosis (1.22, SE 0.07 in presence of $\mathrm{T}$ allele $v s .1 .03$, SE 0.03 for CC genotype, $\mathrm{p}=0.03$ ), lobular inflammation $(39.7 \%$ in presence of $\mathrm{T}$ allele $v$ s. $30.1 \%$ for CC genotype, $\mathrm{p}=0.02)$, and presence of fibrosis $(27.8 \%$ in presence of $\mathrm{T}$ allele $v s .17 .2 \%$ for CC genotype, $\mathrm{p}=0.002$ ) in patients undergoing bariatric surgery (Gorden et al., 2013). NCAN is a proteoglycan involved in remodeling central nervous system extracellular matrix (Rauch et al., 2001), also expressed in the liver (Nischalke et al., 2014).

\section{Protein Phosphatase 1 Regulatory Subunit 3B}

PPP1R3B rs4240624 is associated with CT-diagnosed hepatic steatosis, but not histological evidence of inflammation and fibrosis (Speliotes et al., 2011) and the PPP1R3B rs61756425 variant is a strong predictor of severe NAFLD on ultrasound (OR: 32.6, 95\% CI 4.22-251.4, $\mathrm{p}=$ 0.001) (Di Costanzo et al., 2018). The mutated PPP1R3B results in excess hepatic glycogen (but not triglyceride), resulting in hepatic injury (Stender et al., 2018).

\section{Tribbles Pseudokinase 1}

TRIB1 rs2954021 G > A allele is significantly associated with raised ALT (Chambers et al., 2011) and histologically or ultrasound-diagnosed NAFLD (OR: 1.52, 95\% CI 1.23-1.88, p = 9.7x10-5) (OR: 2.050, 95\% CI 1.110-3.786, p = 0.022) (Kitamoto et al., 2014; Liu et al., 2019). 


\section{Genetic Associations Not Discovered Through Genome Wide Association Studies}

A correlated meta-analysis identified nine ERLIN1-CHUKCWF19L1 gene variants associated with CT-diagnosed NAFLD and raised ALT levels (Feitosa et al., 2013). Phosphatidylethanolamine $\mathrm{N}$-methyltransferase (PEMT) loss of function results in impaired lipid removal from the liver due to reduced levels of hepatic phosphatidylcholine, which mediates triglyceride secretion from hepatocytes (Song et al., 2005; Vance, 2013). Although not demonstrated in GWAS, a meta-analysis of 6 studies showed that the PEMT rs7046 A allele (V175M) is associated with NAFLD in East-Asian populations (OR 1.55, 95\% CI 1.13-2.11, $\mathrm{p}=0.005$ ) (Tan et al., 2016). Mitochondrial transport protein (MTTP) $493 \mathrm{G}>$ T polymorphism is associated with NAFLD ( $\mathrm{G} v$ s. T allele OR: 1.46, 95\% CI 1.20-1.78, p < 0.001), albeit in meta-analysis, not GWAS (Zheng et al., 2014). Superoxide dismutase 2 (SOD2) is involved in removal of reactive oxygen species in mitochondria (Wispe' et al., 1989). In a case-control study of 502 patients with biopsy-proven NAFLD, SOD2 rs4880 was associated with a dose-related increased risk of advanced fibrosis ( $\mathrm{p}=0.008$ for trend) but not steatohepatitis (Al-Serri et al., 2012). Uncoupling protein 2 (UCP2) has a role in regulating lipid efflux and oxidative metabolism, and homozygous $866 \mathrm{G}>\mathrm{A}$ is associated with increased hepatic protein levels and reduced risk of NASH (adjusted OR: 0.49, 95\% CI: 0.26-0.90, p = 0.02) (Fares et al., 2015).

\section{Are There Common Genetic Associations Shared Between Non-Alcoholic Fatty Liver Disease and Cardiovascular Disease?}

Cardiovascular disease is a broad term comprising coronary artery disease $(\mathrm{CAD})$, cerebrovascular disease, and peripheral arterial disease that are largely driven by atherosclerosis (Stewart et al., 2017). While events such as fatal or non-fatal myocardial infarction or stroke may be clinically more meaningful, surrogate markers of CVD including carotid intima-media thickness, carotid artery plaques, and CT-based coronary artery calcification have been used as study endpoints (Patil and Sood, 2017). The genetics of CVD that have identified over 160 loci associated with $\mathrm{CAD}$ at a genome-wide level of significance have been reviewed elsewhere (Erdmann et al., 2018).

PNPLA3 I148M allele had a small, statistically significant (albeit not to GWAS levels of significance) protective effect (OR: $0.92,95 \%$ CI $0.87-0.97, \mathrm{p}=0.002$ ) against CVD, in a metaanalysis of 48 GWAS including 60,801 cases with CVD (Simons et al., 2017). This may relate to reduced levels of circulating triglycerides (Tang et al., 2015). A recent prospective study of patients undergoing elective coronary angiography found that while there was a non-significant trend for a protective effect of the presence of PNPLA3 I148M and CAD $>75 \%$ stenosis, when corrected for age, sex, use of statins, and serum highdensity lipoprotein, there was a significant protective effect (OR: $0.21,95 \%$ CI 0.05-0.88, p = 0.03) (Rüschenbaum et al., 2018). Mendelian randomization has been used to assess the association of PNPLA3 I148M with ischemic heart disease (IHD), and although the risk of IHD increases with increased hepatic fat content, for which PNPLA3 I148M is a risk factor, there was no association with IHD (OR per M allele $=0.98$, 95\% CI 0.95-1.02, $\mathrm{p}=0.79$ ) (Lauridsen et al., 2018).

Interestingly, presence of PNPLA3 I148M variant has been shown to confer a small, but significant risk of premature CAD (defined as MI, angioplasty, revascularization surgery, coronary stenosis $>50 \%$ diagnoses before the age of 55 in men, and 65 in women) only in those with T2DM (OR 1.20, 95\% CI 1.01$1.42, \mathrm{p}=0.042)$, in a study of 1,103 individuals with premature CAD and 1,469 healthy controls (Posadas-Sánchez et al., 2017). Homozygous PNPLA3 I148M genotype confers greater risk of more severe carotid artery intima-media thickness (IMT) in 162 patients with biopsy-proven NAFLD aged $<50$ (OR 2.94, $95 \%$ CI 1.12-7.70, $\mathrm{p}=0.02$ ), validated in 267 patients with clinical or histological NAFLD (Petta et al., 2013).

The TM6SF2 E167K variant which is associated with hepatic steatosis, fibrosis, and HCC development was protective against CVD with lower total cholesterol, LDL-cholesterol, and serum triglycerides in a meta-analysis of 10 studies (Pirola and Sookoian, 2015). A further meta-analysis of 48 GWAS including 60,801 cases with CVD confirmed a small reduction in CVD risk with TM6SF2 E167K (OR: 0.95, 95\% CI 0.92-0.98, p = 0.005) (Simons et al., 2017), and in a smaller cross-sectional study, it was associated with reduced risk of carotid artery plaques (OR: 0.49, 95\% CI 0.25-0.94) (Dongiovanni et al., 2015). As described, this variant is associated with raised serum ALT levels, however a recent Mendelian randomization study has also suggested that raised ALT levels may reduce the risk of IHD, and this may be due to a reduction in serum triglyceride levels (Xu et al., 2017).

PEMT rs12936587 variant was associated with increased susceptibility to CAD (OR 1.07, 95\% CI 1.05-1.09, $\mathrm{p}=4.45 \times 10^{-10}$ ) (Schunkert et al., 2011) in a meta-analysis of 14 GWAS (22,233 cases of CAD and 64,762 controls). However, there was no association with cardiovascular events (IHD, CVA, peripheral arterial disease), and atherosclerosis determined by carotid intima-media wall thickness (IMT) by carotid ultrasonography in a detailed study of 2,609 Spanish individuals (López-Mejías et al., 2017).

TRIB1 rs2954021 variant is associated with increased risk of IHD (15\% increased risk in AA vs. TT genotype, 95\% CI 5-20\%) and MI (17\% increased risk in AA vs. TT genotype, 95\% CI 6-30\%) (Varbo Anette et al., 2011; CARDIoGRAMplusC4D Consortium et al., 2013). TRIB1 rs2954021 and rs231150 are associated with increased risk of coronary heart disease (rs2954021 OR for A vs. $\mathrm{T}$ allele in log-additive model: $1.36,95 \%$ CI $1.14-1.63, \mathrm{p}<0.001$, rs231150 OR for A $v$ s. T allele in log-additive model: $1.36,95 \% \mathrm{CI}$ $1.14-1.63, \mathrm{p}<0.0015)$, and TRIB $1 \mathrm{rs} 2954021$ is also associated with increased risk of ischemic stroke across genetic models (OR for A $v$ s. $\mathrm{T}$ allele in log-additive model: $1.30,95 \%$ CI 1.09-1.55, $\mathrm{p}=0.0039$ ) (Zhang et al., 2019). However, in this study controls were not matched for key risk factors and patients with $\mathrm{CAD}$ and stroke had higher BMI, systolic blood pressure, pulse pressure, and triglyceride levels and lower prevalence of alcohol consumption, and ratio of ApoA1:ApoB.

The clustering of 12 genetic variants associated with NAFLD by weighted fixed-effects statistical modeling showed no association with CAD or MI (OR: 1.00, 95\% CI 0.99-1.01, p = 0.93) (Brouwers et al., 2019). Restricting this analysis to the four 
most validated genes (PNPLA3, TM6SF2, GCKR, and MBOAT7) also resulted in a null association (OR: $0.99,95 \%$ CI $0.98-1.00$ ) (Brouwers et al., 2019).

\section{Discussion and Implications on Treatment of Non-Alcoholic Fatty Liver Disease}

GWAS have identified genes that are associated with NAFLD, many of which have been further validated in observational data. Though GWAS do have certain limitations as described, there are at least 4 genes that have been extensively validated in their association with NAFLD. However, the genes most robustly associated with NAFLD do not appear to contribute to increased cardiovascular risk in terms of CAD, and in fact TM6SF2 E167K is protective against CVD (IHD and ischemic stroke), and PNPLA3 I148M exerts no significant effect on CVD. Where associations have been described in TRIB1 and PEMT (albeit different SNPs), the studies have shown null associations with 'hard' clinical endpoints or suffered incomplete matching of controls. This does not mean that there is no independent association of fatty liver with CVD; rather the complex relationship probably requires much larger studies powered to detect the association as well as Mendelian randomization and interaction studies.

\section{REFERENCES}

Alexander, M., Loomis, A. K., Lei, J. V. D., Duarte-Salles, T., Prieto-Alhambra, D., Ansell, D., et al. (2019a). Non-alcoholic fatty liver disease and risk of incident acute myocardial infarction and stroke: findings from matched cohort study of 18 million European adults. BMJ 367, 15367. doi: 10.1136/bmj.15367

Alexander, M., Loomis, A. K., van der Lei, J., Duarte-Salles, T., Prieto-Alhambra, D., Ansell, D., et al. (2019b). Risks and clinical predictors of cirrhosis and hepatocellular carcinoma diagnoses in adults with diagnosed NAFLD: realworld study of 18 million patients in four European cohorts. BMC Med. 17, 95. doi: 10.1186/s12916-019-1321-x

Al-Serri, A., Anstee, Q. M., Valenti, L., Nobili, V., Leathart, J. B. S., Dongiovanni, P., et al. (2012). The SOD2 C47T polymorphism influences NAFLD fibrosis severity: evidence from case-control and intra-familial allele association studies. J. Hepatol. 56, 448-454. doi: 10.1016/j.jhep.2011.05.029

Angulo, P., Kleiner, D. E., Dam-Larsen, S., Adams, L. A., Bjornsson, E. S., Charatcharoenwitthaya, P., et al. (2015). Liver fibrosis, but no other histologic features, is associated with long-term outcomes of patients with nonalcoholic fatty liver disease. Gastroenterology 149, 389-397.e10. doi: 10.1053/j. gastro.2015.04.043

Anstee, Q. M., and Day, C. P. (2013). The genetics of NAFLD. Nat. Rev. Gastroenterol. Hepatol. 10, 645-655. doi: 10.1038/nrgastro.2013.182

BasuRay, S., Smagris, E., Cohen, J. C., and Hobbs, H. H. (2017). The PNPLA3 variant associated with fatty liver disease (I148M) accumulates on lipid droplets by evading ubiquitylation. Hepatology 66, 1111-1124. doi: 10.1002/hep.29273

Beer, N. L., Tribble, N. D., McCulloch, L. J., Roos, C., Johnson, P. R. V., OrhoMelander, M., et al. (2009). The P446L variant in GCKR associated with fasting plasma glucose and triglyceride levels exerts its effect through increased glucokinase activity in liver. Hum. Mol. Genet. 18, 4081-4088. doi: 10.1093/hmg/ddp357

Brouwers, M. C. G. J., Simons, N., Stehouwer, C. D. A., Koek, G. H., Schaper, N. C., and Isaacs, A. (2019). Relationship between nonalcoholic fatty liver disease susceptibility genes and coronary artery disease. Hepatol. Commun. 3, 587596. doi: 10.1002/hep4.1319

Buch, S., Stickel, F., Trépo, E., Way, M., Herrmann, A., Nischalke, H. D., et al. (2015). A genome-wide association study confirms PNPLA3 and identifies TM6SF2 and MBOAT7 as risk loci for alcohol-related cirrhosis. Nat. Genet. 47, 1443-1448. doi: 10.1038/ng.3417

CARDIoGRAMplusC4D Consortium Deloukas, P., Kanoni, S., Willenborg, C., Farrall, M., Assimes, T. L., et al. (2013). Large-scale association analysis
Given that no drugs are licensed to treat the NAFLD spectrum, management focuses on lifestyle modification. Ideally, therapy would treat liver disease, and also improve clinical endpoints including mortality. Therefore improved patient outcomes may be achieved by interventions that improve control of T2DM, lipids, blood pressure, and obesity rather than have profound effects in the liver. While there is evidence to support a degree of genetic risk in each disease spectrum individually, there is little to no evidence of any shared genetic risk. Therefore while knowledge of genetic loci is potentially useful for risk stratification of patients with NAFLD, therapeutic targeting of the products of these genes as a strategy that improves both liver and cardiovascular health has yet to be proven.

\section{AUTHOR CONTRIBUTIONS}

$\mathrm{KC}$ and WA both wrote and edited the manuscript.

\section{ACKNOWLEDGEMENT}

We are grateful to Professor Panagiotis Deloukas for critical review of the manuscript.

identifies new risk loci for coronary artery disease. Nat. Genet. 45, 25-33. doi: 10.1038/ng.2480

Chalasani, N., Younossi, Z., Lavine, J. E., Diehl, A. M., Brunt, E. M., Cusi, K., et al. (2012). The diagnosis and management of non-alcoholic fatty liver disease: practice guideline by the American association for the study of liver diseases, American College of Gastroenterology, and the American Gastroenterological Association. Hepatology 55, 2005-2023. doi: 10.1002/hep.25762

Chambers, J. C., Zhang, W., Sehmi, J., Li, X., Wass, M. N., Van der Harst, P., et al. (2011). Genome-wide association study identifies loci influencing concentrations of liver enzymes in plasma. Nat. Genet. 43, 1131-1138. doi: 10.1038/ng.970

Chung, G. E., Lee, Y., Yim, J. Y., Choe, E. K., Kwak, M.-S., Yang, J. I., et al. (2018) Genetic Polymorphisms of PNPLA3 and SAMM50 are associated with nonalcoholic fatty liver disease in a Korean Population. Gut Liver 12, 316-323. doi: $10.5009 /$ gnl17306

Di Costanzo, A., Belardinilli, F., Bailetti, D., Sponziello, M., D’Erasmo, L., Polimeni, L., et al. (2018). Evaluation of polygenic determinants of nonalcoholic fatty liver disease (NAFLD) by a candidate genes resequencing strategy. Sci. Rep. 8, 3702. doi: 10.1038/s41598-018-21939-0

Donati, B., Dongiovanni, P., Romeo, S., Meroni, M., McCain, M., Miele, L., et al. (2017). MBOAT7 rs641738 variant and hepatocellular carcinoma in noncirrhotic individuals. Sci. Rep. 7, 4492. doi: 10.1038/s41598-017-04991-0

Dongiovanni, P., Petta, S., Maglio, C., Fracanzani, A. L., Pipitone, R., Mozzi, E., et al. (2015). Transmembrane 6 superfamily member 2 gene variant disentangles nonalcoholic steatohepatitis from cardiovascular disease. Hepatol. Baltim. 61, 506-514. doi: 10.1002/hep.27490

Erdmann, J., Kessler, T., Munoz Venegas, L., and Schunkert, H. (2018). A decade of genome-wide association studies for coronary artery disease: the challenges ahead. Cardiovasc. Res. 114, 1241-1257. doi: 10.1093/cvr/cvy084

Eslam, M., Valenti, L., and Romeo, S. (2018). Genetics and epigenetics of NAFLD and NASH: Clinical impact. J. Hepatol. 68, 268-279. doi: 10.1016/j. jhep.2017.09.003

Fares, R., Petta, S., Lombardi, R., Grimaudo, S., Dongiovanni, P., Pipitone, R., et al. (2015). The UCP2 $-866 \mathrm{G}>\mathrm{A}$ promoter region polymorphism is associated with nonalcoholic steatohepatitis. Liver Int. 35, 1574-1580. doi: 10.1111/liv.12707

Feitosa, M. F., Wojczynski, M. K., North, K. E., Zhang, Q., Province, M. A., Carr, J. J., et al. (2013). The ERLIN1-CHUK-CWF19L1 gene cluster influences liver 
fat deposition and hepatic inflammation in the NHLBI Family Heart Study. Atherosclerosis 228, 175-180. doi: 10.1016/j.atherosclerosis.2013.01.038

Francque, S. M., Graaff, D. V. D., and Kwanten, W. J. (2016). Non-alcoholic fatty liver disease and cardiovascular risk: pathophysiological mechanisms and implications. J. Hepatol. 65, 425-443. doi: 10.1016/j.jhep.2016.04.005

Gorden, A., Yang, R., Yerges-Armstrong, L. M., Ryan, K. A., Speliotes, E., Borecki, I. B., et al. (2013). Genetic variation at NCAN locus is associated with inflammation and fibrosis in non-alcoholic fatty liver disease in morbid obesity. Hum. Hered. 75, 34-43. doi: 10.1159/000346195

Huang, Y., Cohen, J. C., and Hobbs, H. H. (2011). Expression and Characterization of a PNPLA3 Protein Isoform (I148M) Associated with nonalcoholic fatty liver disease. J. Biol. Chem. 286, 37085-37093. doi: 10.1074/jbc.M111.290114

Kawaguchi, T., Sumida, Y., Umemura, A., Matsuo, K., Takahashi, M., Takamura, T., et al. (2012). Genetic polymorphisms of the human PNPLA3 gene are strongly associated with severity of non-alcoholic fatty liver disease in Japanese. PloS One 7, e38322. doi: 10.1371/journal.pone.0038322

Kitamoto, T., Kitamoto, A., Yoneda, M., Hyogo, H., Ochi, H., Nakamura, T., et al. (2013). Genome-wide scan revealed that polymorphisms in the PNPLA3, SAMM50, and PARVB genes are associated with development and progression of nonalcoholic fatty liver disease in Japan. Hum. Genet. 132, 783-792. doi: 10.1007/s00439-013-1294-3

Kitamoto, A., Kitamoto, T., Nakamura, T., Ogawa, Y., Yoneda, M., Hyogo, H., et al. (2014). Association of polymorphisms in GCKR and TRIB1 with nonalcoholic fatty liver disease and metabolic syndrome traits. Endocr. J. 61, 683-689. doi: 10.1507/endocri.EJ14-0052

Koo, B. K., Joo, S. K., Kim, D., Bae, J. M., Park, J. H., Kim, J. H., et al. (2018). Additive effects of PNPLA3 and TM6SF2 on the histological severity of nonalcoholic fatty liver disease. J. Gastroenterol. Hepatol. 33, 1277-1285. doi: 10.1111 /jgh.14056

Kozlitina, J., Smagris, E., Stender, S., Nordestgaard, B. G., Zhou, H. H., TybjærgHansen, A., et al. (2014). Exome-wide association study identifies a TM6SF2 variant that confers susceptibility to nonalcoholic fatty liver disease. Nat. Genet. 46, 352-356. doi: 10.1038/ng.2901

López-Mejías, R., Corrales, A., Vicente, E., Robustillo-Villarino, M., GonzálezJuanatey, C., Llorca, J., et al. (2017). Influence of coronary artery disease and subclinical atherosclerosis related polymorphisms on the risk of atherosclerosis in rheumatoid arthritis. Sci. Rep. 7, 40303. doi: 10.1038/srep40303

Lauridsen, B. K., Stender, S., Kristensen, T. S., Kofoed, K. F., Køber, L., Nordestgaard, B. G., et al. (2018). Liver fat content, non-alcoholic fatty liver disease, and ischaemic heart disease: Mendelian randomization and meta-analysis of 279 013 individuals. Eur. Heart J. 39, 385-393. doi: 10.1093/eurheartj/ehx662

Lazo, M., Hernaez, R., Bonekamp, S., Kamel, I. R., Brancati, F. L., Guallar, E., et al. (2011). Non-alcoholic fatty liver disease and mortality among US adults: prospective cohort study. BMJ 343, d6891. doi: 10.1136/bmj.d6891

Liu, H., and Lu, H.-Y. (2014). Nonalcoholic fatty liver disease and cardiovascular disease. World J. Gastroenterol. 20, 8407-8415. doi: 10.3748/wjg.v20.i26.8407

Liu, Y.-L., Patman, G. L., Leathart, J. B. S., Piguet, A.-C., Burt, A. D., Dufour, J.-F., et al. (2014a). Carriage of the PNPLA3 rs738409 C > G polymorphism confers an increased risk of non-alcoholic fatty liver disease associated hepatocellular carcinoma. J. Hepatol. 61, 75-81. doi: 10.1016/j.jhep.2014.02.030

Liu, Y.-L., Reeves, H. L., Burt, A. D., Tiniakos, D., McPherson, S., Leathart, J. B. S., et al. (2014b). TM6SF2 rs58542926 influences hepatic fibrosis progression in patients with non-alcoholic fatty liver disease. Nat. Commun. 5, 4309. doi: 10.1038/ncomms5309

Liu, Q., Xue, F., Meng, J., Liu, S.-S., Chen, L.-Z., Gao, H., et al. (2019). TRIB1 rs17321515 and rs2954029 gene polymorphisms increase the risk of nonalcoholic fatty liver disease in Chinese Han population. Lipids Health Dis. 18, 61. doi: 10.1186/s12944-019-1001-z

Mahdessian, H., Taxiarchis, A., Popov, S., Silveira, A., Franco-Cereceda, A., Hamsten, A., et al. (2014). TM6SF2 is a regulator of liver fat metabolism influencing triglyceride secretion and hepatic lipid droplet content. Proc. Natl. Acad. Sci. 111, 8913-8918. doi: 10.1073/pnas.1323785111

Mahfood Haddad, T., Hamdeh, S., Kanmanthareddy, A., and Alla, V. M. (2017). Nonalcoholic fatty liver disease and the risk of clinical cardiovascular events: A systematic review and meta-analysis. Diabetes Metab. Syndr. Clin. Res. Rev. 11, S209-S216. doi: 10.1016/j.dsx.2016.12.033

Mancina, R. M., Dongiovanni, P., Petta, S., Pingitore, P., Meroni, M., Rametta, R., et al. (2016). The MBOAT7-TMC4 variant rs641738 increases risk of nonalcoholic fatty liver disease in individuals of European descent. Gastroenterology 150, 1219-1230.e6. doi: 10.1053/j.gastro.2016.01.032

Morrison, A. E., Zaccardi, F., Khunti, K., and Davies, M. J. (2019). Causality between non-alcoholic fatty liver disease and risk of cardiovascular disease and type 2 diabetes: a meta-analysis with bias analysis. Liver Int. 39, 557-567. doi: 10.1111/liv.13994

Nischalke, H. D., Lutz, P., Krämer, B., Söhne, J., Müller, T., Rosendahl, J., et al. (2014). A common polymorphism in the NCAN gene is associated with hepatocellular carcinoma in alcoholic liver disease. J. Hepatol. 61, 1073-1079. doi: 10.1016/j.jhep.2014.06.006

Onuma, H., Tabara, Y., Kawamoto, R., Shimizu, I., Kawamura, R., Takata, Y., et al. (2010). The GCKR rs780094 polymorphism is associated with susceptibility of type 2 diabetes, reduced fasting plasma glucose levels, increased triglycerides levels and lower HOMA-IR in Japanese population. J. Hum. Genet. 55, 600604. doi: 10.1038/jhg.2010.75

Patil, R., and Sood, G. K. (2017). Non-alcoholic fatty liver disease and cardiovascular risk. World J. Gastrointest. Pathophysiol. 8, 51-58. doi: 10.4291/wjgp.v8.i2.51

Petta, S., Valenti, L., Marchesini, G., Marco, V. D., Licata, A., Cammà, C., et al. (2013). PNPLA3 GG Genotype and Carotid Atherosclerosis in Patients with Non-Alcoholic Fatty Liver Disease. PloS One 8, e74089. doi: 10.1371/journal. pone. 0074089

Petta, S., Miele, L., Bugianesi, E., Cammà, C., Rosso, C., Boccia, S., et al. (2014). Glucokinase regulatory protein gene polymorphism affects liver fibrosis in non-alcoholic fatty liver disease. PloS One 9, e87523. doi: 10.1371/journal. pone. 0087523

Pingitore, P., Pirazzi, C., Mancina, R. M., Motta, B. M., Indiveri, C., Pujia, A., et al. (2014). Recombinant PNPLA3 protein shows triglyceride hydrolase activity and its I148M mutation results in loss of function. Biochim. Biophys. Acta BBA Mol. Cell Biol. Lipids 1841, 574-580. doi: 10.1016/j.bbalip.2013.12.006

Pingitore, P., Dongiovanni, P., Motta, B. M., Meroni, M., Lepore, S. M., Mancina, R. M., et al. (2016). PNPLA3 overexpression results in reduction of proteins predisposing to fibrosis. Hum. Mol. Genet. 25, 5212-5222. doi: $10.1093 / \mathrm{hmg} / \mathrm{ddw} 341$

Pirazzi, C., Valenti, L., Motta, B. M., Pingitore, P., Hedfalk, K., Mancina, R. M., et al. (2014). PNPLA3 has retinyl-palmitate lipase activity in human hepatic stellate cells. Hum. Mol. Genet. 23, 4077-4085. doi: 10.1093/hmg/ddu121

Pirola, C. J., and Sookoian, S. (2015). The dual and opposite role of the TM6SF2 -rs58542926 variant in protecting against cardiovascular disease and conferring risk for nonalcoholic fatty liver: a meta-analysis: Hepatology, Month 2015. Hepatology 62, 1742-1756. doi: 10.1002/hep.28142

Posadas-Sánchez, R., López-Uribe, Á. R., Posadas-Romero, C., PérezHernández, N., Rodríguez-Pérez, J. M., Ocampo-Arcos, W. A., et al. (2017). Association of the I148M/PNPLA3 (rs738409) polymorphism with premature coronary artery disease, fatty liver, and insulin resistance in type 2 diabetic patients and healthy controls. The GEA study. Immunobiology 222, 960-966. doi: 10.1016/j.imbio.2016.08.008

Rüschenbaum, S., Schwarzkopf, K., Friedrich-Rust, M., Seeger, F., Schoelzel, F., Martinez, Y., et al. (2018). Patatin-like phospholipase domain containing 3 variants differentially impact metabolic traits in individuals at high risk for cardiovascular events. Hepatol. Commun. 2, 798-806. doi: 10.1002/hep4.1183

Rafiq, N., Bai, C., Fang, Y., Srishord, M., McCullough, A., Gramlich, T., et al. (2009). Long-term follow-up of patients with nonalcoholic fatty liver. Clin. Gastroenterol. Hepatol. 7, 234-238. doi: 10.1016/j.cgh.2008.11.005

Rauch, U., Feng, K., and Zhou, X.-H. (2001). Neurocan: a brain chondroitin sulfate proteoglycan. Cell. Mol. Life Sci. CMLS 58, 1842-1856. doi: 10.1007/ PL00000822

Rodríguez, M. L., Silva, L. F., Vangipurapu, J., Modi, S., Kuusisto, J., Kaikkonen, M. U., et al. (2018). Functional variant in the GCKR gene affects lactate levels differentially in the fasting state and during hyperglycemia. Sci. Rep. 8, 1-8. doi: 10.1038/s41598-018-34501-9

Romeo, S., Kozlitina, J., Xing, C., Pertsemlidis, A., Cox, D., Pennacchio, L. A., et al. (2008). Genetic variation in PNPLA3 confers susceptibility to nonalcoholic fatty liver disease. Nat. Genet. 40, 1461-1465. doi: 10.1038/ng.257

Rotman, Y., Koh, C., Zmuda, J. M., Kleiner, D. E., and Liang, T. J. (2010). The association of genetic variability in patatin-like phospholipase domaincontaining protein 3 (PNPLA3) with histological severity of nonalcoholic fatty liver disease. Hepatology 52, 894-903. doi: 10.1002/hep.23759 
Söderberg, C., Stål, P., Askling, J., Glaumann, H., Lindberg, G., Marmur, J., et al. (2010). Decreased survival of subjects with elevated liver function tests during a 28-year follow-up. Hepatology 51, 595-602. doi: 10.1002/hep.23314

Schunkert, H., König, I. R., Kathiresan, S., Reilly, M. P., Assimes, T. L., Holm, H., et al. (2011). Large-scale association analysis identifies 13 new susceptibility loci for coronary artery disease. Nat. Genet. 43, 333-338. doi: $10.1038 /$ ng.784

Simons, N., Isaacs, A., Koek, G. H., Kuč, S., Schaper, N. C., and Brouwers, M. C. G. J. (2017). PNPLA3, TM6SF2, and MBOAT7 genotypes and coronary artery isease. Gastroenterology 152, 912-913. doi: 10.1053/j.gastro.2016.12.020

Singal, A. G., Manjunath, H., Yopp, A. C., Beg, M. S., Marrero, J. A., Gopal, P., et al. (2014). The effect of PNPLA3 on fibrosis progression and development of hepatocellular carcinoma: a meta-analysis. Am. J. Gastroenterol. 109, 325-334. doi: 10.1038/ajg.2013.476

Song, J., Costa, K. A., Fischer, L. M., Kohlmeier, M., Kwock, L., Wang, S., et al. (2005). Polymorphism of the PEMT gene and susceptibility to nonalcoholic fatty liver disease (NAFLD). FASEB J. Off. Publ. Fed. Am. Soc Exp. Biol. 19, 1266-1271. doi: 10.1096/fi.04-3580com

Sookoian, S., Castaño, G. O., Burgueño, A. L., Gianotti, T. F., Rosselli, M. S., and Pirola, C. J. (2009). A nonsynonymous gene variant in the adiponutrin gene is associated with nonalcoholic fatty liver disease severity. J. Lipid Res. 50, $2111-$ 2116. doi: 10.1194/jlr.P900013-JLR200

Sparsø, T., Andersen, G., Nielsen, T., Burgdorf, K. S., Gjesing, A. P., Nielsen, A. L., et al. (2008). The GCKR rs780094 polymorphism is associated with elevated fasting serum triacylglycerol, reduced fasting and OGTT-related insulinaemia, and reduced risk of type 2 diabetes. Diabetologia 51, 70-75. doi: 10.1007/ s00125-007-0865-Z

Speliotes, E. K., Yerges-Armstrong, L. M., Wu, J., Hernaez, R., Kim, L. J., Palmer, C. D., et al. (2011). Genome-wide association analysis identifies variants associated with nonalcoholic fatty liver disease that have distinct effects on metabolic traits. PloS Genet. 7, e1001324. doi: 10.1371/journal.pgen.1001324

Stender, S., Smagris, E., Lauridsen, B. K., Kofoed, K. F., Nordestgaard, B. G., Tybjærg-Hansen, A., et al. (2018). Relationship between genetic variation at PPP1R3B and levels of liver glycogen and triglyceride. Hepatology 67, 21822195. doi: 10.1002/hep.29751

Stepanova, M., and Younossi, Z. M. (2012). Independent association between nonalcoholic fatty liver disease and cardiovascular disease in the US population. Clin. Gastroenterol. Hepatol. 10, 646-650. doi: 10.1016/j.cgh.2011.12.039

Stewart, J., Manmathan, G., and Wilkinson, P. (2017). Primary prevention of cardiovascular disease: a review of contemporary guidance and literature. JRSM Cardiovasc. Dis. 6. doi: 10.1177/2048004016687211

Tam, V., Patel, N., Turcotte, M., Bossé, Y., Paré, G., and Meyre, D. (2019). Benefits and limitations of genome-wide association studies. Nat. Rev. Genet. 20, 467484. doi: 10.1038/s41576-019-0127-1

Tan, H. M., Mohamed, R. B., Mohamed, Z., and Zain, S. M. (2016). Phosphatidylethanolamine N-methyltransferase gene rs7946 polymorphism plays a role in risk of nonalcoholic fatty liver disease: evidence from meta-analysis. Pharmacogenet. Genomics 26, 88-95. doi: 10.1097/FPC.0000000000000193

Tang, C. S., Zhang, H., Cheung, C. Y. Y., Xu, M., Ho, J. C. Y., Zhou, W., et al. (2015). Exome-wide association analysis reveals novel coding sequence variants associated with lipid traits in Chinese. Nat. Commun. 6, 1-9. doi: 10.1038/ ncomms 10206

Targher, G., Byrne, C. D., Lonardo, A., Zoppini, G., and Barbui, C. (2016). Nonalcoholic fatty liver disease and risk of incident cardiovascular disease: A metaanalysis. J. Hepatol. 65, 589-600. doi: 10.1016/j.jhep.2016.05.013

Valenti, L., Al-Serri, A., Daly, A. K., Galmozzi, E., Rametta, R., Dongiovanni, P., et al. (2010). Homozygosity for the patatin-like phospholipase-3/adiponutrin I148M polymorphism influences liver fibrosis in patients with nonalcoholic fatty liver disease. Hepatol. Baltim. 51, 1209-1217. doi: 10.1002/hep.23622

Vance, D. E. (2013). Physiological roles of phosphatidylethanolamine N-methyltransferase. Biochim. Biophys. Acta BBA Mol. Cell Biol. Lipids 1831, 626-632. doi: 10.1016/j.bbalip.2012.07.017
Varbo Anette, B. M., Tybjærg-Hansen, A., Grande, P., and Nordestgaard Børge, G. (2011). TRIB1 and GCKR Polymorphisms, lipid levels, and risk of ischemic heart disease in the general population. Arterioscler. Thromb. Vasc. Biol. 31, 451-457. doi: 10.1161/ATVBAHA.110.216333

Wang, X., Liu, Z., Wang, K., Wang, Z., Sun, X., Zhong, L., et al. (2016). Additive effects of the risk alleles of PNPLA3 and TM6SF2 on non-alcoholic fatty liver disease (NAFLD) in a Chinese population. Front. Genet. 7, 140. doi: 10.3389/ fgene.2016.00140

White, D. L., Kanwal, F., and El-Serag, H. B. (2012). Non-Alcoholic Fatty Liver Disease and Hepatocellular Cancer: A Systematic Review. Clin. Gastroenterol. Hepatol. Off. Clin. Pract. J. Am. Gastroenterol. Assoc. 10, 1342-1359.e2. doi: 10.1016/j.cgh.2012.10.001

Wispe', J. R., Clark, J. C., Burhans, M. S., Kropp, K. E., Korfhagen, T. R., and Whitsett, J. A. (1989). Synthesis and processing of the precursor for human mangano-superoxide dismutase. Biochim. Biophys. Acta BBA Protein Struct. Mol. Enzymol. 994, 30-36. doi: 10.1016/0167-4838(89)90058-7

Wu, S., Wu, F., Ding, Y., Hou, J., Bi, J., and Zhang, Z. (2016). Association of non-alcoholic fatty liver disease with major adverse cardiovascular events: A systematic review and meta-analysis. Sci. Rep. 6, 33386. doi: 10.1038/srep33386

Xu, L., Jiang, C. Q., Lam, T. H., Zhang, W. S., Zhu, F., Jin, Y. L., et al. (2017). Mendelian randomization estimates of alanine aminotransferase with cardiovascular disease: Guangzhou Biobank Cohort study. Hum. Mol. Genet. 26, 430-437. doi: 10.1093/hmg/ddw396

Younossi, Z. M., Koenig, A. B., Abdelatif, D., Fazel, Y., Henry, L., and Wymer, M. (2016). Global epidemiology of nonalcoholic fatty liver disease-Meta-analytic assessment of prevalence, incidence, and outcomes. Hepatol. Baltim. 64, 73-84. doi: 10.1002/hep.28431

Younossi, Z. M., Stepanova, M., Rafiq, N., Henry, L., Loomba, R., Makhlouf, H., et al. (2017). Nonalcoholic steatofibrosis independently predicts mortality in nonalcoholic fatty liver disease. Hepatol. Commun. 1, 421-428. doi: 10.1002/ hep4.1054

Younossi, Z. M. (2019). Non-alcoholic fatty liver disease - A global public health perspective. J. Hepatol. 70, 531-544. doi: 10.1016/j.jhep.2018.10.033

Zain, S. M., Mohamed, Z., and Mohamed, R. (2015). Common variant in the glucokinase regulatory gene rs780094 and risk of nonalcoholic fatty liver disease: a meta-analysis. J. Gastroenterol. Hepatol. 30, 21-27. doi: 10.1111/ jgh.12714

Zeb, I., Li, D., Budoff, M. J., Katz, R., Lloyd-Jones, D., Agatston, A., et al. (2016). Nonalcoholic fatty liver disease and incident cardiac events: the multi-ethnic study of atherosclerosis. J. Am. Coll. Cardiol. 67, 1965-1966. doi: 10.1016/j. jacc.2016.01.070

Zhang, Q.-H., Yin, R.-X., Chen, W.-X., Cao, X.-L., and Wu, J.-Z. (2019). TRIB1 and TRPS1 variants, $G \times G$ and $G \times E$ interactions on serum lipid levels, the risk of coronary heart disease and ischemic stroke. Sci. Rep. 9, 2376. doi: 10.1038/ s41598-019-38765-7

Zheng, W., Wang, L., Su, X., and Hu, X.-F. (2014). MTP -493G > T Polymorphism and susceptibility to nonalcoholic fatty liver disease: a meta-analysis. DNA Cell Biol. 33, 361-369. doi: 10.1089/dna.2013.2238

Conflict of Interest: WA has received speaking honoraria and consultancy fees from Gilead, Intercept, GSK, Allergan, and Goldman Sachs.

The remaining author declares that the research was conducted in the absence of any commercial or financial relationships that could be construed as a potential conflict of interest.

Copyright $\odot 2020$ Chandrasekharan and Alazawi. This is an open-access article distributed under the terms of the Creative Commons Attribution License (CC BY). The use, distribution or reproduction in other forums is permitted, provided the original author(s) and the copyright owner(s) are credited and that the original publication in this journal is cited, in accordance with accepted academic practice. No use, distribution or reproduction is permitted which does not comply with these terms. 